\title{
Conhecimento e mudanças nas condutas clínicas dos cirurgiões-dentistas da ESF de Maceió frente à pandemia de COVID-19
}

\author{
Knowledge and changes in clinical behavior of Maceio ESF dental surgeons facing \\ COVID-19 pandemic
}

\author{
Mirela Godoi Nunes de Oliveira ${ }^{1}$ \\ Orcid: https://orcid.org/0000-0003-2287-7930 \\ Isabelle Cristina de Oliveira Vieira ${ }^{3}$ \\ Orcid: https://orcid.org/0000-0002-1074-7330
}

\author{
Aline Costa Cardoso ${ }^{2}$ \\ Orcid: https://orcid.org/0000-0001-5568-1243
}

João Alfredo Tenório Lins Guimarães ${ }^{4}$

Orcid: https://orcid.org/0000-0002-4035-401X

\section{Resumo}

O processo de adequação dos cirurgiões-dentistas às medidas de biossegurança e controle da infecção frente à pandemia de COVID-19 é relevante, visto que a equipe de saúde bucal tem na região orofacial sua área de atuação. A Estratégia de Saúde da Família (ESF) exerce um papel central em tais emergências sanitárias. Sendo assim, o objetivo do estudo é identificar o nível de conhecimento, as mudanças ocorridas nas condutas clínicas e no comportamento dos cirurgiões-dentistas da ESF de Maceió nos atendimentos odontológicos durante a pandemia de COVID-19. Trata-se de um estudo descritivo, de corte transversal e abordagem quantitativa, cujos dados são provenientes da aplicação de um questionário a 20 cirurgiões-dentistas das equipes de saúde bucal vinculadas a ESF. Vinte e cinco por cento $(25 \%)$ dos voluntários da pesquisa testaram positivo para a doença. Uma mudança considerável pós-pandemia foi a adoção dos protetores faciais nas rotinas profissionais dos cirurgiões-dentistas - 95\% passaram a usá-los. Aproximadamente, 68,42\% passaram a atender apenas urgências/emergências. A clorexidina $0,12-0,2 \%$ foi o colutório pré-procedimento mais utilizado $(68,42 \%)$ como método de diminuição da carga viral. Setenta e cinco por cento (75\%) dos profissionais enfrentaram problemas na obtenção de equipamentos de proteção individual. A maioria (55\%) fez uma autoavaliação considerando seu conhecimento suficiente, mas apenas $40 \%$ concluíram um curso a respeito do tema. A maior parte dos cirurgiões-dentistas da ESF de Maceió tem tido um bom desempenho em suas condutas clínicas frente às diretrizes propostas. Entretanto, observa-se a ausência de capacitações e treinamentos para sanar algumas fragilidades na aprendizagem de sinais/sintomas e utilização de colutórios antimicrobianos.

Palavras-chave: assistência integral à saúde; COVID-19; odontologia em saúde pública; atenção primária à saúde; contenção de riscos biológicos.

\begin{abstract}
The adaptation process of dentists to biosafety measures and infection control facing the COVID-19 pandemic is relevant, once the oral healthcare team has its area of expertise in the orofacial region. The Family Health Strategy (ESF - Estratégia de Saúde da Família) plays a central role in such health emergencies. Therefore, the objective of the study is to identify the
\end{abstract}

\footnotetext{
${ }^{1}$ Cirurgiã-dentista Especialista em Saúde da Família - Universidade Estadual de Ciências da Saúde de Alagoas- UNCISAL, Brasil. E-mail: mirela.mgno@gmail.com

${ }^{2}$ Enfermeira Especialista em Saúde da Família - Universidade Estadual de Ciências da Saúde de Alagoas - UNCISAL, Brasil. E-mail: alinecardoso.c@outlook.com

${ }^{3}$ Profa. Mestra, Cirurgiã-dentista Especialista em Vigilância em Saúde, - Universidade Federal de Alagoas - UFAL, Brasil. E-mail: vieirabelle@hotmail.com

${ }^{4}$ Cirurgião-dentista, Prof. Mestre - Universidade Estadual de Ciências da Saúde de Alagoas - UNCISAL, Brasil. E-mail:

joaolegista@globo.com
} 
level of knowledge, changes in the clinical attitude and behavior of ESF dental surgeons in Maceió regarding dental care during the COVID-19 pandemic. This is a descriptive and crosssectional study with a quantitative approach. Its data come from the application of a questionnaire to 20 dental surgeons from the oral health teams linked to the ESF. Twenty-five percent $(25 \%)$ of the research volunteers tested positive for the disease. A considerable change after the pandemic was the use of facial-shields in the dental routines - 95\% started wearing them. Approximately $68.42 \%$ of the dentists started only to attend to urgencies / emergencies. Chlorhexidine $0.12-0.2 \%$ was the most used pre-procedure mouthwash $(68.42 \%)$ as a method of decreasing viral load. Seventy-five percent $(75 \%)$ of professionals faced problems in obtaining personal protective equipment. The majority $(55 \%)$ made a self-assessment considering their knowledge sufficient, but only $40 \%$ completed a course on the topic. Most of the ESF dental surgeons in Maceió have had a good performance in their clinical procedures concerning to the proposed guidelines. However, there is a lack of qualification and training to remedy some weaknesses in the learning process of signs / symptoms and the use of antimicrobial mouthwashes.

Keywords: comprehensive health care; COVID-19; public health dentistry; primary health care; containment of biohazards.

\section{Introdução}

A doença COVID-19 causada pelo vírus SARS-CoV-2, um vírus de RNA, também conhecido como novo coronavírus, tem provocado casos de Síndrome Aguda Respiratória Grave (SARG) apresentando sintomas como dispneia, prostração, febre, tosse, diarreia, anosmia, ageusia entre outros $^{1}$. Esses quadros foram, inicialmente, detectados no final de 2019, após um surto ocorrido na cidade de Wuhan, China, onde se verificou a rápida transmissibilidade da nova forma viral ${ }^{2}$.

Alguns meses depois, em 11 de Março de 2020, foi declarada a pandemia de COVID-19 pela Organização Mundial da Saúde (OMS), visto que o vírus se espalhou pelos continentes causando várias mortes e confirmando o seu poder de contágio e ameaça ao ser humano. De acordo com a OMS, 107,252,265 pessoas foram infectadas e 2,355,339 já morreram pelo SARS-CoV-2 em todo o mundo até $11 \mathrm{de}$ fevereiro de $2021^{3}$.

A doença é transmitida através de gotículas que ficam no ar por algum tempo, as quais são expelidas ao falar e durante o ato da respiração, podendo ser aspiradas por outras pessoas. Ao entrar em contato com as mucosas nasal, bucal ou ocular, essas gotículas contendo partículas virais são capazes de contaminar indivíduos saudáveis ${ }^{4}$.
Além disso, o vírus pode permanecer em algumas superfícies por um longo período de tempo. Assim, aumenta-se o risco de contágio pelo ato de tocar em superfícies contaminadas e levar as mãos às mucosas. Logo, as maneiras de prevenção da transmissão são: a correta higienização das mãos com água e sabão ou com álcool gel a 70\%, na impossibilidade da lavagem destas, o uso de máscaras por todos os indivíduos, o uso de equipamentos de proteção individuais (EPIs) pelos profissionais dos serviços de saúde e outros serviços essenciais, desinfecção frequente de superfícies com produtos regularizados na Agência Nacional de Vigilância Sanitária (ANVISA) e o distanciamento social $^{5}$.

Estudos têm mostrado que o SARSCov-2 apresenta um período de incubação de, em média, 5 dias podendo chegar a 14 dias, o que tem justificado o período de quarentena adotado de duas semanas ${ }^{6}$. Segundo o Ministério da Saúde $^{7}$, já foram mais de 9 milhões e 200 mil indivíduos infectados no Brasil, com 225.099 óbitos por COVID-19 até 02 de fevereiro de 2021. Alagoas chegou a alcançar a posição de $15^{\circ}$ estado com maior número de casos confirmados durante o pico da pandemia ${ }^{8}$, sendo que 51.534 casos e 1.374 óbitos de residentes em Maceió ocorreram só na capital do estado, até 23 de fevereiro de $2021^{9}$. 
De acordo com estudos na área, $80 \%$ dos casos da doença são leves ${ }^{10}$. Diante disso, a Atenção Primária à Saúde (APS), sobretudo a Estratégia de Saúde da Família (ESF), exerce um papel central em situações sanitárias emergenciais como a COVID-19. A ESF tem como atribuições o monitoramento dos casos suspeitos e leves, em adição à função importantíssima de prestar suporte às famílias diante dos desafios econômicos e sociais decorrentes da pandemia, bem como do agravamento de doenças crônicas, uma vez que a ESF tem um entendimento ampliado dos determinantes de saúde da população assistida $^{11}$.

Além das adversidades advindas para a população geral, a COVID-19 traz um risco ocupacional aumentado para os trabalhadores dos serviços de saúde devido ao seu alto risco de contágio ${ }^{4}$. Estima-se que, no Brasil, cerca de 944.238 profissionais de saúde apresentaram quadros de Síndrome Gripal (SG) suspeitos de COVID-19, e destes, 195.516 (20,7\%) casos foram confirmados para a infecção pelo SARS-CoV-2 durante o pico da pandemia, até o mês de julho de $2020^{12}$. A partir do início de 2021, até o dia 18 de janeiro, foram notificados 29.853 casos novos de SG suspeitos de COVID-19, dentre os quais $5.419(18,1 \%)$ foram confirmados para a infecção ${ }^{13}$.

Os profissionais que trabalham na área buco-nasal estão sob um risco ainda maior de contrair a doença pelo fato destas estarem intimamente ligadas ao processo de transmissão das partículas virais. Dentre estes, está a equipe de saúde bucal (eSB) composta pelos cirurgiões-dentistas, os técnicos e assistentes de saúde bucal, a qual está exposta rotineiramente ao contato próximo face a face e a aerossóis contendo água, saliva e sangue e outros fluídos orais gerados pelos equipamentos próprios da prática laboral ${ }^{4}$.

Os cuidados com a desinfecção das superfícies, com a paramentação e desparamentação dos trabalhadores das eSBs têm que ser realizados cada vez mais frequentemente para que se evite a contaminação da equipe. Os agentes de desinfecção recomendados para as superfícies inanimadas são hipoclorito de sódio $1 \%$; quaternário de amônio 7 - 9\%; ácido peracético; e álcool líquido $70 \%$. Tal procedimento deve ser executado antes do início dos atendimentos e após cada atendimento ${ }^{5}$.

Também, deve-se garantir que a eSB realize a paramentação e desparamentação de forma ordenada e use respiradores N95 ou PFF2 para procedimentos que gerem aerossóis, roupas e pijamas cirúrgicos, bem como máscara cirúrgica, gorro, luvas e avental/jaleco descartáveis, óculos e protetores faciais (face-shields) ${ }^{5}$.

Segundo dados coletados na Gerência de Saúde Bucal da Secretaria Municipal de Saúde de Maceió (SMS), 35 eSBs atuam vinculadas a equipes de Saúde da Família dos 08 Distritos Sanitários (DS) de Maceió. Seguindo as diretrizes do MS e da ANVISA, através das Notas Técnicas $\mathrm{N}^{\circ}$ 9/2020-CGSB/DESF/SAPS/MS ${ }^{14} \mathrm{e} \quad \mathrm{N}^{\mathrm{o}}$ 04/2020 GVIMS/GGTES/ANVISA ${ }^{15}$, a Gerência orientou os servidores públicos, no início do mês de abril de 2020, no que se refere ao atendimento das urgências e emergências em odontologia, com postergação das consultas e procedimentos eletivos de forma que se diminua o risco ao profissional.

Sendo assim, tendo em vista a importância da APS na situação emergencial da pandemia de COVID-19 e atentando ao retorno dos atendimentos eletivos, faz-se relevante evidenciar como tem ocorrido o processo de adequação dos profissionais de saúde, sobretudo da eSB quanto à COVID-19 nas medidas de biossegurança tomadas para diminuição da infecção cruzada, em relação ao conhecimento adquirido em diversos meios, tais como cursos e palestras relativos ao tema, bem como treinamentos de capacitação técnica que corroborem para a ocorrência de um controle eficiente da infecção. 
Desta maneira, objetiva-se nesse estudo identificar o nível de conhecimento, as mudanças ocorridas nas condutas clínicas e no comportamento dos cirurgiões-dentistas da ESF de Maceió em relação ao atendimento odontológico durante a pandemia de COVID-19.

\section{Materiais e Métodos}

\section{Amostra e tipo de estudo}

Trata-se de um estudo descritivo, de corte transversal e abordagem quantitativa, cujos dados são provenientes da aplicação de um questionário online estruturado aos cirurgiões-dentistas das eSBs vinculadas a ESF em Maceió, sendo a amostragem do tipo não probabilística por conveniência.

$\mathrm{O}$ número total de cirurgiõesdentistas que fazem parte da ESF da cidade de Maceió é de 35 profissionais. Foram convidados a participar da pesquisa todos os cirurgiões-dentistas da ESF de Maceió, totalizando 35 profissionais, possíveis participantes da pesquisa. Destes, 20 aceitaram participar voluntariamente da pesquisa compondo a amostra do estudo. Um (01) deles respondeu por e-mail informando que não participaria da pesquisa devido ao fato de estar cumprindo licença, por fazer parte do grupo de risco para a COVID-19. Os demais não responderam o questionário e não se pronunciaram quanto à falta de desejo em se voluntariar como participantes de pesquisa.

Este estudo foi submetido à análise do Comitê de Ética em Pesquisa (CEP) da Universidade Estadual de Ciências da Saúde de Alagoas (UNCISAL) e, aprovado com CAAE 36388920.8.0000.5011.

\section{Delineamento da pesquisa}

A coleta de dados foi realizada exclusivamente de forma on-line durante todo o mês de outubro de 2020 por meio do envio de um questionário estruturado disponibilizado na plataforma Google Forms ${ }^{\circledR}$ enviado por e-mail. O instrumento de coleta de dados foi adaptado a partir de instrumentos previamente validados e utilizados nos estudos de Duruk, Gümüşboğa e Çolak ${ }^{16}$ e Cagetti et al. ${ }^{17}$. O questionário foi adaptado à realidade local e ao momento vivido pelos profissionais. Foram abordadas questões sobre especialidade, estado de saúde, ocorrência de sinais/sintomas, conhecimento relacionado à COVID-19 e medidas de proteção adotadas na rotina clínica após a declaração da pandemia pela OMS.

\section{Critérios de Inclusão e Exclusão}

Os participantes foram cirurgiõesdentistas de eSBs vinculadas à Estratégia de Saúde da Família do município de Maceió. Foram excluídos do estudo os cirurgiõesdentistas que estavam de férias ou cumprindo licença iniciada antes da declaração do estado de pandemia. É importante salientar que não foi possível determinar o número de dentistas em férias ou cumprindo licença, pois esse dado foi solicitado duas vezes via e-mail à área técnica responsável na Secretaria Municipal de Saúde, infelizmente, sem êxito, porquanto não foi obtida resposta

\section{Procedimentos}

Primeiramente foi obtida a autorização formal da Secretaria Municipal de Saúde de Maceió (SMS) para coleta de dados, após sua autorização o projeto foi submetido ao Comitê de Ética em Pesquisa através da Plataforma Brasil. Assim, em posse da autorização do Comitê de Ética, os pesquisadores solicitaram os dados de contato de e-mail dos cirurgiões-dentistas à área técnica da SMS. Então, uma lista com os e-mails deles foi disponibilizada aos pesquisadores. Os responsáveis da SMS informaram aos profissionais via Whatsapp ${ }^{\circledR}$ a respeito da pesquisa e que seriam contatados pelos pesquisadores via e-mail.

Os e-mails enviados aos participantes continham a explicação dos objetivos e da importância do estudo. Assim, mediante à leitura dos termos de realização da pesquisa e, no caso de aceite, 
estes, no meio virtual/digital, assinalaram uma caixa onde afirmaram ter entendido o objetivo da pesquisa e aceitaram o Termo de Consentimento Livre e Esclarecido.

Após a coleta de dados, estes foram armazenados em planilha eletrônica (Microsoft Excel 2010®. Redmond, WA, EUA). Os resultados foram tabulados e as frequências das variáveis de cada grupo calculadas e dispostas em gráficos e tabelas.

\section{Resultados}

A idade média dos 20 participantes foi $44,2 \pm 3,5$ (38-50) anos, e foram predominantemente mulheres $(90 \%)$. Em relação às especialidades, apenas uma pessoa respondeu não ter especialidade. Uma pessoa não informou a especialidade. Dos voluntários, $40 \%$ apresentavam uma especialidade; e 35\%, duas.

Quando questionados sobre serem ou não portadores de doenças crônicas com uso de medicação regular, $15 \%$ responderam que "sim". Vinte e cinco por cento $(25 \%)$ testaram positivo para a doença até o momento da pesquisa. Setenta e cinco por cento $(75 \%)$ por cento dos profissionais afirmaram não ter apresentado nenhum sinal ou sintoma de COVID-19. Os principais sinais/sintomas relatados e a porcentagem dos infectados pelo Sars-CoV2 que apresentaram o respectivo sinal/sintoma estão descritos na Tabela 1 .

Tabela 1: Principais sinais e sintomas relatados pelos participantes que testaram positivo para COVID-19.

\begin{tabular}{ccc}
\hline Sinal/sintoma & $\mathrm{n}$ & $\%$ \\
\hline Diarreia & 1,00 & 20,00 \\
Febre & 1,00 & 25,00 \\
Tosse & 2,00 & 40,00 \\
Congestão Nasal & 2,00 & 40,00 \\
Coriza & 2,00 & 40,00 \\
Dor de cabeça & 3,00 & 60,00 \\
Fadiga & 3,00 & 60,00 \\
Dor de garganta & 3,00 & 60,00 \\
Dor no corpo & 3,00 & 60,00 \\
Anosmia (perda de olfato) & 4,00 & 80,00 \\
Ageusia (perda de paladar) & 4,00 & 80,00 \\
\hline
\end{tabular}

Número de participantes que testaram positivo p/ COVID-19: total=05; $n$, número de participantes que testaram positivo para a infecção por COVID-19 para cada sinal/sintoma relatado; \%, porcentagem dos infectados pelo Sars-CoV-2 que apresentaram o respectivo sinal/sintoma.

Porém, alguns dos participantes que responderam não ter tido sinais/sintomas de COVID-19, quando perguntados: "Você apresentou um ou mais desses sinais/sintomas?" - afirmaram ter apresentado alguns sinais/sintomas característicos de COVID-19. Esses dados foram dispostos na Tabela 2. Esses participantes equivalem a $60 \%$ daqueles que inicialmente responderam não ter tido sinais/sintomas.

Tabela 2: Sinais/sintomas dos participantes que testaram negativo ou que não foram testados para COVID-19.

\begin{tabular}{ccc}
\hline Sinal/sintoma & $\mathrm{n}$ & $\%$ \\
\hline Diarreia & 3,00 & 20,00 \\
Febre & 1,00 & 6,67 \\
Tosse & 1,00 & 6,67 \\
Congestão Nasal & 3,00 & 20,00 \\
Coriza & 1,00 & 6,67 \\
Dor de cabeça & 3,00 & 33,34 \\
Fadiga & 1,00 & 6,67 \\
Dor de garganta & 2,00 & 13,34 \\
\hline Sem sinal/sintoma & 6,00 & 40,00
\end{tabular}

Número de participantes com teste negativo ou sem teste $\mathrm{p}$ / COVID-19: total=15; $\mathrm{n}$, número de participantes com teste negativo ou sem teste $\mathrm{p}$ / COVID-19 para cada sinal/sintoma relatado; \%, porcentagem dos participantes com testagem negativa ou sem testagem para o Sars-CoV-2 que apresentaram o respectivo sinal/sintoma. 
Em relação às fontes de informação sobre a COVID-19, 100\% responderam que recebiam a informação de websites/mídias sociais de órgãos oficiais como Ministério da Saúde, OMS e conselhos profissionais; $90 \%$ de websites/mídias sociais de profissionais de saúde; $85 \%$ de grupos de comunicação, como grupos de Whatsapp; $60 \%$ da TV; $50 \%$ participaram de eventos como seminários, palestras e congressos (presencial ou on-line) e apenas $40 \%$ de curso (presencial ou on-line).
A autoavaliação dos dentistas sobre o conhecimento da COVID-19 está disposta no (Gráfico 1).

Gráfico 1: Autoavaliação dos cirurgiões-dentistas da ESF de Maceió a respeito do conhecimento sobre a COVID-19. Os dentistas se autoavaliaram por meio das 05 respostas apresentadas (não tenho conhecimento, insuficiente, moderado, suficiente e compreendo muito bem), as quais indicam níveis diferentes de conhecimento quanto à infecção pelo vírus Sars-CoV-2 quando submetidos à pergunta: "O quanto você considera ser o seu conhecimento sobre COVID-19?".

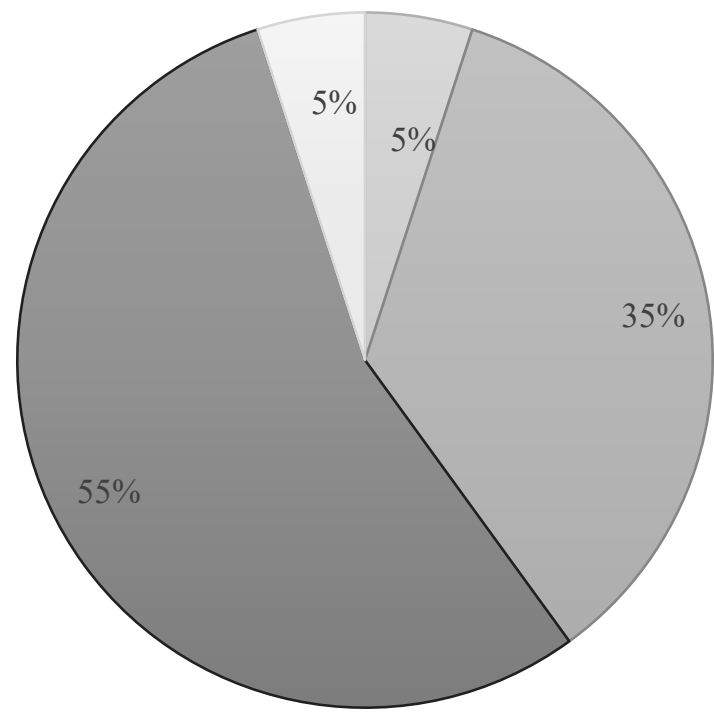

$\square$ Não tenho conhecimento $\square$ Insuficiente $\square$ Moderado $\square$ Suficiente $\square$ Compreende muito bem

Ao serem questionados se realizaram alguma mudança contra a COVID-19 na sua rotina profissional em relação aos atendimentos odontológicos no Sistema Único de Saúde (SUS), 40\% do número total de dentistas voluntários (total=20) relataram uma redução no número de atendimentos, $65 \%$ declararam realizar apenas atendimentos de urgência/emergência, e 5\%, que equivale a 01 participante, relataram ter parado os atendimentos por completo. Quanto às medidas contra a COVID-19 tomadas na rotina profissional, 95\% dos voluntários responderam que passaram usar protetores faciais (face-shields); $80 \%$ respiradores N95; 75\%, óculos de proteção; 95\%, aventais descartáveis.

As medidas de precaução adotadas pós COVID-19 e as normas de biossegurança previamente executadas na rotina odontológica dos 19 dentistas que continuaram a realizar atendimentos pelo SUS podem ser visualizadas na Tabela 3 .

Tabela 3: Medidas de precaução tomadas pelos cirurgiões-dentistas da ESF de Maceió que continuaram a trabalhar após a declaração da pandemia pela Organização Mundial da Saúde.

\begin{tabular}{lcc} 
& Medida & n (\%) \\
\hline Antes das consultas & Redução do número de atendimentos & $6,00(31,58)$ \\
\hline
\end{tabular}




\begin{tabular}{|c|c|c|}
\hline (Planejamento) & $\begin{array}{c}\text { Realização apenas de atendimentos de urgência/emergência } \\
\text { Adiamento do atendimento de pacientes idosos ou com } \\
\text { doenças sistêmicas } \\
\text { Adiamento do atendimento de pacientes potencialmente } \\
\text { infectados por } 14 \text { dias }\end{array}$ & $\begin{array}{l}13,00(68,42) \\
11,00(57,89)\end{array}$ \\
\hline \multirow{3}{*}{$\begin{array}{l}\text { Na sala de espera } \\
\text { (Pré-atendimento) }\end{array}$} & $\begin{array}{c}\text { Avaliação das condições de saúde do paciente (se } \\
\text { apresentam sintomas, como tosse e febre) antes do } \\
\text { atendimento odontológico }\end{array}$ & $15,00(78,95)$ \\
\hline & $\begin{array}{l}\text { Atendimentos mais espaçados para não encher a sala de } \\
\text { espera }\end{array}$ & $16,00(84,21)$ \\
\hline & Solicitação da lavagem das mãos do paciente & $4,00(21,05)$ \\
\hline \multirow{14}{*}{$\begin{array}{l}\text { No consultório } \\
\text { (Atendimento) }\end{array}$} & Máscara N95 & $16,00(84,21)$ \\
\hline & Avental descartável & $19,00(100,00)$ \\
\hline & $\begin{array}{l}\text { Lavagem frequente das mãos (antes e depois de cada } \\
\text { atendimento) }\end{array}$ & $19,00(100,00)$ \\
\hline & Higiene das mãos com álcool gel 70\% & $19,00(100,00)$ \\
\hline & Desinfecção das superfícies com álcool líquido $70 \%$ & $17,00(89,47)$ \\
\hline & Desinfecção das superfícies com hipoclorito de sódio $0,5 \%$ & $8,00(42,10)$ \\
\hline & Uso de isolamento absoluto & $0,00(0,00)$ \\
\hline & $\begin{array}{l}\text { Bochechos com clorexidina } 0,12-0,2 \% \text { antes de iniciar os } \\
\text { procedimentos }\end{array}$ & $13,00(68,42)$ \\
\hline & Bochechos com peróxido de hidrogênio 1\% & $2,00(10,52)$ \\
\hline & Bochechos com iodopovidona $0,2-1 \%$ & $0,00(0,00)$ \\
\hline & Uso de sistema de sucção de alta potência (bomba a vácuo) & $0,00(0,00)$ \\
\hline & Uso de instrumento rotatório com válvula anti-retração & $0,00(0,00)$ \\
\hline & Evito todos os procedimentos que possam gerar aerossóis & $15,00(78,95)$ \\
\hline & $\begin{array}{c}\text { Remoção de todos os dispositivos de proteção descartáveis e } \\
\text { desinfecção de dispositivos não descartáveis após cada } \\
\text { atendimento }\end{array}$ & $16(84,21)$ \\
\hline
\end{tabular}

Total de dentistas participantes que continuaram atendendo durante a pandemia $=19 ; \mathrm{n}$, número de participantes que realizaram a medida mencionada; $(\%)$, porcentagem dos participantes que realizaram a medida mencionada.

Dez por cento (10\%) dos participantes responderam que a gestão de onde trabalham não realizou nenhuma mudança com relação às normas e/ou orientações para atendimento devido à COVID-19; cinco por cento (5\%) informaram que a gestão orientou a reduzir o número de atendimentos odontológicos; e oitenta e cinco por cento $(85 \%)$ relataram que foram orientados ao atendimento de urgências e emergências.

No que tange aos desafios encarados no trabalho durante a pandemia de COVID$19,75 \%$ por cento disseram que tinham dificuldades na obtenção de equipamentos de proteção individual; $50 \%$ por cento consideraram que o nível de conhecimento dos técnicos e assistentes a respeito do assunto é baixo; e $20 \%$ por cento relataram não ter encontrado nenhum problema durante esse período.

Todos os voluntários do estudo disseram acreditar que é muito provável que a infecção por SARS-CoV-2 seja um risco para o dentista. Da mesma maneira, todos afirmaram estarem preocupados em transmitir a doença a alguém do seu convívio domiciliar devido a sua profissão fazer parte do grupo de risco para a COVID19. A maioria dos participantes, $95 \%$, afirmou que, como cirurgião-dentista, informa os seus pacientes sobre a COVID19. 


\section{Discussão}

Predominaram participantes mulheres no estudo $(90 \%)$ em conformidade com as pesquisas realizadas com dentistas brasileiros, cujas maiorias foram de $68,58 \%{ }^{18}$ e $72,92 \%{ }^{19}$ de voluntárias do sexo feminino. Estudos realizados na Itália e na Turquia demonstraram uma predominância de participantes do sexo masculino ${ }^{16,17}$. $\mathrm{Na}$ Polônia, observou-se uma tendência semelhante à brasileira ${ }^{20}$.

Um estudo de letalidade da COVID19, levando em conta fatores socioeconômicos e demográficos, revelou que "as chances de mortes de um paciente preto ou pardo analfabeto (76\%) são 3,8 vezes maiores que um paciente branco com nível superior $(19,6 \%)$, confirmando as enormes disparidades no acesso e qualidade do tratamento no Brasil" ${ }^{21}$. Outro estudo brasileiro expõe a maior vulnerabilidade de indígenas e pobres à COVID-19, sendo sua prevalência entre indígenas $6,4 \%$, mais de quatro vezes maior que a prevalência em pessoas brancas $(1,4 \%)^{22}$. A alta prevalência entre povos indígenas acontece devido às condições de moradia, pobreza $\mathrm{e}$ dificuldades no acesso à saúde ${ }^{22}$.

Por isso, é importante destacar que apenas $25 \%$ dos participantes do presente estudo testaram positivo para COVID-19, nenhum deles foi hospitalizado ou teve complicações decorrentes da doença até a finalização dessa pesquisa. Esses resultados podem estar diretamente vinculados às condições socioeconômicas dos participantes, uma vez que todos possuem nível superior e $40 \%$ possuem pelo menos uma especialização, o que contribui para uma melhor situação econômica e acesso à saúde.

Um estudo realizado em Pernambuco com 363 participantes demonstrou uma menor porcentagem de dentistas que testaram positivo para a doença, apenas $6,1 \%$, o que expressa uma proporção bem menor de infectados em comparação a amostra da presente pesquisa realizada em Maceió. No referido estudo,
$22 \%$ dos participantes não possuíam pósgraduação $^{23}$.

Pacientes com comorbidades apresentam maior risco de infecção pelo SARS-CoV-2. Situações críticas podem se desenvolver em indivíduos com hipertensão, diabetes, DPOC (doença pulmonar obstrutiva crônica), doenças cardíacas, malignidades e HIV (vírus da imunodeficiência humana). Pacientes com DPOC desenvolvem substancialmente sintomas graves e taxas de mortalidade comparativamente mais altas ${ }^{24}$. Entretanto, na pesquisa realizada, nenhum dos voluntários que teve a doença confirmada tinha algum tipo de doença sistêmica crônica e/ou apresentou a forma grave da doença - a SARG. Os principais sinais e sintomas relatados pelos participantes são compatíveis com os apresentados na literatura ${ }^{17,18,19,24 .}$.

Embora a maioria dos dentistas (55\%) tenha autoavaliado seu conhecimento como suficiente a respeito da infecção pelo SARS-CoV-2, destes, 75\% responderam que não haviam tido sinal/sintoma de COVID-19 e na pergunta seguinte quando perguntados: "Você apresentou um ou mais desses sinais/sintomas?" - afirmaram ter apresentado alguns sinais/sintomas característicos da doença contradizendo a sua autoavaliação de que teriam conhecimento suficiente sobre o assunto, uma vez que não reconheceram sintomas característicos da doença como um alerta para uma possível triagem e testagem.

É importante ressaltar que entre esses participantes existe a possibilidade de ter ocorrido casos de testagem negativa, porém não se deve descartar o risco de infecção pelo SARS-CoV-2 sem a devida testagem, tendo os profissionais, possivelmente, cumprido suas atividades laborais apresentando sinais/sintomas característicos, o que pode se traduzir num elevado contágio para os seus colegas de trabalho e para a comunidade atendida pelo serviço de saúde. 
Uma mudança considerável póspandemia foi a adoção dos protetores faciais nas rotinas profissionais dos cirurgiõesdentistas $-95 \%$ passaram a usá-los - , tendo sido uma medida recomendada pela ANVISA $^{15}$ e que foi aplicada tanto pelos participantes da pesquisa como também em diversos serviços relatados na literatura ${ }^{16,}$ 19, 20 . Essa alteração é bastante significativa devido ao fato desse EPI representar uma diminuição do risco à exposição aos materiais biológicos, proporcionado pela geração de aerossóis durante os procedimentos ${ }^{15}$.

A ANVISA tornou obrigatório o uso dos respiradores N95/PFF2 ou equivalente pelo profissional de saúde para a realização de procedimentos odontológicos visando à diminuição do risco de contaminação, podendo estes serem reutilizados, desde que pelo mesmo profissional, com o uso de protetor facial (para diminuição da contaminação do respirador por gotículas), seguindo a NOTA TÉCNICA GVIMS/GGTES/ANVISA N $\mathrm{N}^{\circ} 04 / 2020$ e protocolo definido pelo serviço de saúde ${ }^{15}$. A maioria dos voluntários relatou fazer uso dos referidos respiradores, conforme $\mathrm{o}$ recomendado pela Agência. Da mesma forma, eles tem feito o uso de aventais descartáveis, os quais têm sido regulamentados e exigidos pelo órgão.

Em relação aos colutórios antimicrobianos, pré-procedimento, a Agência Nacional de Vigilância Sanitária tem recomendado o uso de agentes de oxidação (ex.: peróxido de hidrogênio de 0,5 a $1 \%$ ou iodopovidona a $0,2 \%$ ), com o objetivo de reduzir a carga viral. A clorexidina parece não ser eficaz ${ }^{15}$. A literatura tem demonstrado que, embora o iodopovidona esteja relacionado a casos de hipersensibilidade, tem exibido atividade antiviral, assim como o peróxido de hidrogênio, porém a ação da clorexidina precisa de mais estudos relacionados ao SARS-CoV-2 para ser definida ${ }^{4,25,26}$. A maioria dos participantes tem agido em desconformidade ao recomendado na literatura, uma vez que $68,42 \%$ disponibilizaram clorexidina $0,12-0,2 \%$ como colutório pré-procedimento aos pacientes, apenas 10,52\% disponibilizaram peróxido de hidrogênio $1 \%$, e nenhum deles ofereceu iodopovidona $0,2-1 \%$ aos seus pacientes.

Um estudo realizado em Istambul, Turquia também revelou uma tendência semelhante dos dentistas na utilização da clorexidina antes de procedimentos odontológicos $(61,7 \%)$, ficando em segundo lugar o uso do peróxido de hidrogênio $(52 \%)$ e em terceiro o uso de iodopovidona $(43,1 \%)^{27}$. Embora o estudo demonstre que ocorreu uso da iodopovidona, isso não ocorreu na presente pesquisa.

Durante os atendimentos, os estudos pertinentes ${ }^{16,17} \mathrm{e}$ a ANVISA $^{15}$ orientam à aspiração contínua da saliva residual, se possível com sistema de sucção de alta potência (bomba a vácuo). A limpeza das mangueiras que compõem o sistema de sucção deve ser realizada, ao término de cada atendimento, com desinfetante a base de cloro na concentração de $2500 \mathrm{mg}$ de cloro por litro de água ${ }^{15}$. Entretanto, nenhum dos participantes disse ter acesso a esse tipo de sistema nos serviços de saúde nos quais trabalham.

No que diz respeito às fontes de informação, é necessário ressaltar a importância da procedência das informações às quais os cirurgiões-dentistas se submetem ${ }^{16,18}$. Na literatura é possível perceber um direcionamento da maioria dos profissionais para a busca de informações nos sites de órgãos oficiais, entretanto existe também um considerável número de participantes que tem como procedência dados a partir das redes sociais ${ }^{16,17,28}$, as quais não se constituem em fontes consideradas confiáveis.

Apesar de todos os voluntários buscarem dados e esclarecimentos a partir de websites como os do Ministério da Saúde e da OMS, menos da metade - apenas $40 \%$ - se matricularam em algum curso. A capacitação e o treinamento por meio de cursos e palestras configura uma Educação 
Permanente em Saúde (EPS) para o serviço de saúde.

É essencial destacar que atividades de EPS são fundamentais para $o$ aperfeiçoamento dos processos de trabalho e poderiam ter diminuído algumas fragilidades como as questões das dúvidas dos sinais/sintomas e dos colutórios. A EPS é muito relevante para a segurança do paciente e qualidade, visto que a educação constitui uma prática essencial na construção de uma assistência mais segura e de qualidade ao paciente ${ }^{29}$.

Acerca das ações da gestão, é interessante evidenciar que seria necessário a oferta de cursos e capacitações sobre a temática para os profissionais, pois em alguns pontos existem fragilidades. Além da ausência desse apoio técnico, observa-se também uma falta de recursos materiais para a prestação da assistência à saúde, pois, segundo a pesquisa, a maior parte dos voluntários teve dificuldades na obtenção de EPI (75\%). Entretanto, vale salientar, que vários municípios brasileiros enfrentaram problemas para compra de material médico-hospitalar durante o surto de COVID- $19^{30}$.

A gestão, por meio da Gerência de Saúde Bucal da Secretaria Municipal de Saúde de Maceió (SMS), agiu de forma apropriada ao emitir uma nota em abril de 2020 de acordo com as determinações da ANVISA orientando os cirurgiões-dentistas ao adiamento dos procedimentos que não fossem clinicamente urgentes ou emergenciais ${ }^{15}$.

Pela natureza da profissão, os cirurgiões-dentistas estão expostos a patógenos localizados nas cavidades orais e vias respiratórias dos pacientes. O risco dos dentistas de contração COVID-19 é um dos mais altos entre todas as profissões da área da saúde ${ }^{20}$. Isso reflete no estado psicológico dos profissionais, pois todos os participantes acreditam que é muito provável que a infecção por SARS-CoV-2 seja um risco para si mesmos, além de todos estarem preocupados em transmitir a doença a alguém do seu convívio familiar devido à sua profissão.

Um estudo apontou que mais de $80 \%$ dos cirurgiões-dentistas estavam sendo psicologicamente afetados pela COVID$19^{16}$, enquanto outro revelou que apesar de ter conhecimento e ter modificado os seus serviços de acordo com as diretrizes recomendadas, dentistas em todo o mundo estão em um estado de ansiedade e medo enquanto trabalham em seus respectivos campos, devido ao impacto da pandemia de COVID-19 na humanidade ${ }^{31}$.

\section{Conclusão}

Apesar de todos os obstáculos e desafios impostos pela pandemia de COVID-19, os cirurgiões-dentistas da ESF de Maceió, em sua maioria, têm conseguido ter um bom desempenho nas suas condutas clínicas frente às novas diretrizes que têm sido propostas, tanto pela OMS, quanto pelo Ministério da Saúde e pela ANVISA, além de ter demonstrado um bom nível de conhecimento a respeito do tema. Entretanto, observa-se a ausência de capacitações e treinamentos que pudessem funcionar como Educação Permanente nos serviços de saúde e sanar algumas fragilidades em relação a aprendizagem dos sinais/sintomas e dos colutórios antimicrobianos pré-procedimentos que podem ser utilizados de forma mais eficaz para controle da infecção.

\section{Referências}

1. Iser BP, Sliva I, Raymundo VT, Poleto MB, Schuelter-Trevisol F, Bobinski F. Definição de caso suspeito da COVID-19: uma revisão narrativa dos sinais e sintomas mais frequentes on os casos confirmados. Epidemiol Serv Saude. 2020 Jun 22;29:e2020233. 
2. Phelan AL, Katz R, Gostin LO. The novel coronavirus originating in Wuhan, China: challenges for global health governance. Jama. $2020 \mathrm{Fev}$ 25;323(8):709-10.

3. WHO. World Health Organization. Coronavirus disease (COVID-19) pandemic: WHO Coronavirus Disease (COVID-19) Dashboard [Internet], $2021 \mathrm{Fev}$. [Acesso em $2021 \mathrm{Fev}$ 12] Disponível em: https://covid19.who.int/. Acesso em: 12 fev. 2021.

4. Peng X, Xu X, Li Y, Cheng L, Zhou X, Ren B. Transmission routes of 2019-nCoV and controls in dental practice. Int J Oral Sci. 2020 Mar 3;12(1):1-6.

5. CFO (Brasil). Conselho Federal de Odontologia. Manual de boas práticas em biossegurança para ambientes odontológicos. [Internet]. E-book: Conselho Federal de Odontologia, 2020 [citado em $202010 \mathrm{Fev}$ ]. Disponível em: https://website.cfo.org.br/wpcontent/uploads/2020/04/cfo-lanc\%CC\%A7a-Manual-de-Boas-Pra\%CC\%81ticas-emBiosseguranc\%CC\%A7a-para-Ambientes-Odontologicos.pdf

6. Backer JA, Klinkenberg D, Wallinga J. Incubation period of 2019 novel coronavirus (2019$\mathrm{nCoV}$ ) infections among travellers from Wuhan, China, 20-28 January 2020. Euro Surveill. 2020 Fev 6;25(5):2000062.

7. Painel Coronavírus. [Internet] Brasil: Ministério da Saúde. 2021 - [citado em 2 fev. 2021] Disponível em: https://covid.saude.gov.br/.

8. COVID-19: Painel do Coronavírus - Coronavírus-Brasil. [Internet] Brasil: Ministério da Saúde - Secretaria de Vigilância em Saúde, 2020 Jul. 21- [citado em 23 Jul. 2021]. Disponível em: https://covid.saude.gov.br/.

9. Informe Epidemiológico COVID-19: Cenário Epidemiológico Maceió / AL. In: Boletim Coronavírus [Internet]. Maceió: Gerência de Vigilância das Doenças e Agravos Transmissíveis e Não Transmissíveis - Secretaria Municipal de Saúde, 23 Fev. 2021 [citado em 24 Mar. 2021]. Disponível em: http://www.maceio.al.gov.br/wpcontent/uploads/2021/02/pdf/2021/02/Boletim-covid-19-n.\%C2\%BA-234-de-23-defevereiro-de-2021-SE-07\%C2\%AA.pdf.

10. Novel CP. The epidemiological characteristics of an outbreak of 2019 novel coronavirus diseases (COVID-19) in China. Zhonghua liu xing bing xue za zhi= Zhonghua liuxingbingxue zazhi. $2020 \mathrm{Fev}$ 17;41(2):145.

11. Sarti TD, Lazarini WS, Fontenelle LF, Almeida AP. Qual o papel da Atenção Primária à Saúde diante da pandemia provocada pela COVID-19?. Epidemiol Serv Saude. 2020; 29 (2): e2020166.

12. COVID-19: Painel do Coronavírus - Coronavírus-Brasil. [Internet] Brasil: Ministério da Saúde - Secretaria de Vigilância em Saúde, 2020 Jul. 20 - [citado em 21 Jul. 2021]. Disponível em: https://covid.saude.gov.br/.

13. Boletim Epidemiológico Especial: Semana Epidemiológica 2 (10 a 16/01/21). In: Boletins Epidemiológicos. [Internet] Brasil: Ministério da Saúde, 2021- [citado em 02 fev. 2021]. Disponível em: https://www.gov.br/saude/ptbr/media/pdf/2021/janeiro/22/boletim_epidemiologico_covid_46-final.pdf.

14. NOTA TÉCNICA No 9/2020-CGSB/DESF/SAPS/MS. COVID-19 E ATENDIMENTO ODONTOLÓGICO NO SUS, [Internet]. Brasília - DF: Ministério da Saúde/SAPS Secretaria de Atenção Primária à Saúde, Março 2020 - [citado em 23 jul. 2020]. Disponível em: http://website.cfo.org.br/wp-content/uploads/2020/03/COVID-19_ATENDIMENTOODONTOLOGICO-NO-SUS.pdf. 
15. NOTA TÉCNICA GVIMS/GGTES/ANVISA Nº 04/2020. Orientações para serviços de saúde: medidas de prevenção e controle que devem ser adotadas durante a assistência aos casos suspeitos ou confirmados de infecção pelo novo coronavírus (SARS-CoV-2). [Internet]. Brasil: ANVISA - Agência Nacional de Vigilância Sanitária, Março 2020 [citado em 23 jul. 2020] Disponível em: http://portal.anvisa.gov.br/documents/33852/271858/Nota+T\%C3\%A9cnica+n+042020+GVIMS-GGTES-ANVISA/ab598660-3de4-4f14-8e6f-b9341c196b28.

16. Duruk G, Gümüşboğa ZŞ, Çolak C. Investigation of Turkish dentists' clinical attitudes and behaviors towards the COVID-19 pandemic: a survey study. Braz Oral Res. 2020;34.

17. Cagetti MG, Cairoli JL, Senna A, Campus G. COVID-19 outbreak in North Italy: an overview on dentistry. A questionnaire survey. Int J Environ Res Public Health. 2020 Jan;17(11):3835.

18. Vieira-Meyer AP, Coutinho MB, Santos HP, Saintrain MV, Candeiro GT. Brazilian Primary and Secondary Public Oral Health Attention: Are Dentists Ready to Face the COVID-19 Pandemic?. Disaster Med Public Health Prep. 2020 Sep 10:1-8.

19. Candeiro GT, Gavini G, Vivan RR, Carvalho BM, Duarte MA, FeijÃo CP. Knowledge about Coronavirus disease 19 (COVID-19) and its professional repercussions among Brazilian endodontists. Braz Oral Res. 2020;34.

20. Tysiąc-Miśta M, Dziedzic A. The attitudes and professional approaches of dental practitioners during the COVID-19 outbreak in Poland: a cross-sectional survey. Int J Environ Res Public Health. 2020 Jan;17(13):4703.

21. Batista A, Antunes B, Faveret G, Peres I, Marchesi J, Cunha JP. Análise socioeconômica da taxa de letalidade da COVID-19 no Brasil. Núcleo de Operações e Inteligência em Saúde (NOIS). 2020 May 27.

22. Hallal PC, Hartwig FP, Horta BL, Silveira MF, Struchiner CJ, Vidaletti LP, Neumann NA, Pellanda LC, Dellagostin OA, Burattini MN, Victora GD. SARS-CoV-2 antibody prevalence in Brazil: results from two successive nationwide serological household surveys. Lancet Glob Health. 2020 Nov 1;8(11):e1390-8.

23. Gaspar Gabriela da Silveira, Figueiredo Nilcema, Lucena Edson Hilan Gomes de, Ceissler Cindy Avani Silva, Cavalcanti Ronald Pereira, Goes Paulo Sávio Angeiras de. Characterization of Dental Surgeons of Pernambuco State in the COVID-19 Pandemic Context: Preliminary Data. Pesqui. Bras. Odontopediatria Clín. Integr. [Internet]. 2020. Available from: http://www.scielo.br/scielo.php?script=sci_arttext\&pid=S1983$46322020001500302 \& \operatorname{lng}=$ en. Epub Aug 31, 2020.

24. Ejaz H, Alsrhani A, Zafar A, Javed H, Junaid K, Abdalla AE, Abosalif KO, Ahmed Z, Younas S. COVID-19 and comorbidities: Deleterious impact on infected patients. J Infect Public Health. 2020 Aug 4.

25. Carrouel F, Gonçalves LS, Conte MP, Campus G, Fisher J, Fraticelli L, Gadea-Deschamps E, Ottolenghi L, Bourgeois D. < ? covid19?> Antiviral Activity of Reagents in Mouth Rinses against SARS-CoV-2. J Dent Res. 2020 Oct 22:0022034520967933.

26. Seneviratne CJ, Balan P, Ko KK, Udawatte NS, Lai D, Ng DH, Venkatachalam I, Lim KS, Ling ML, Oon L, Goh BT. Efficacy of commercial mouth-rinses on SARS-CoV-2 viral load in saliva: Randomized Control Trial in Singapore. Infection. 2020 Dec 14:1-7.

27. Sezgin GP, Şirinoğlu Çapan B. Assessment of dentists' awareness and knowledge levels on the Novel Coronavirus (COVID-19). Braz Oral Res. 2020;34. 
28. De Stefani A, Bruno G, Mutinelli S, Gracco A. COVID-19 outbreak perception in Italian dentists. Int J Environ Res Public Health. 2020 Jan;17(11):3867.

29. Koerich C, Erdmann AL, Lanzoni GM. Interação profissional na gestão da tríade: educação permanente em saúde, segurança do paciente e qualidade. Rev Lat Am Enfermagem. 2020;28.

30. Sodré F. Epidemia de Covid-19: questões críticas para a gestão da saúde pública no Brasil. Trabalho, Educação e Saúde. 2020;18(3).

31. Ahmed MA, Jouhar R, Ahmed N, Adnan S, Aftab M, Zafar MS, Khurshid Z. Fear and practice modifications among dentists to combat novel coronavirus disease (COVID-19) outbreak. Int J Environ Res Public Health. 2020 Jan;17(8):2821.

\section{Como citar este artigo:}

Oliveira MGN, Cardoso AC, Vieira ICO, Guimarães JATL. Conhecimento e mudanças nas condutas clínicas dos cirurgiões-dentistas da ESF de Maceió frente à pandemia de COVID-19. Rev. Aten. Saúde. 2021; 19(68): 287-299. 